\title{
Oral saline consumption and pressor responses to acute physical stress
}

\author{
J.J. DEL VECCHIO, P.A. HOSICK and E.L. MATTHEWS*
}

Department of Exercise Science and Physical Education, Montclair State University, Montclair, NJ, USA

Received: December 13, 2019 • Accepted: May 15, 2020

Published online: July 16, 2020

(C) 2020 Akadémiai Kiadó, Budapest

\begin{abstract}
Sodium induced volume loading may alter pressor responses to physical stress, an early symptom of cardiovascular disease. Purpose: Study 1: Determine the time point where total blood volume and serum sodium were elevated following saline consumption. Study 2: Examine the BP response to isometric handgrip (HG) and the cold pressor test (CPT) following saline consumption. Methods: Study 1: Eight participants drank $423 \mathrm{~mL}$ of normal saline (sodium $154 \mathrm{mmol} / \mathrm{L}$ ) and had blood draws every $30 \mathrm{~min}$ for 3 h. Study 2: Sixteen participants underwent two randomized data collection visits; a control and experimental visit $90 \mathrm{~min}$ following saline consumption. Participants underwent $2 \mathrm{~min}$ of isometric HG, post exercise ischemia (PEI), and CPT. Results: Study 1: Total blood volume $(3.8 \pm 3.0 \Delta \%)$ and serum sodium $(3.5 \pm 3.6 \Delta \%)$ were elevated $(P<0.05)$ by the $90 \mathrm{~min}$ time point. Study 2 : There were no differences in mean arterial pressure (MAP) during HG (EXP: $17.4 \pm 8.2 \Delta \mathrm{mmHg}$; CON: $19.1 \pm 6.0 \Delta \mathrm{mmHg}$ ), PEI (EXP: $16.9 \pm 11.7 \Delta \mathrm{mmHg}$; CON: $16.9 \pm 7.8 \Delta \mathrm{mmHg}$ ), or the CPT (EXP: $20.3 \pm 10.8 \Delta \mathrm{mmHg}$; CON: $20.9 \pm$ $11.7 \Delta \mathrm{mmHg})$ between conditions $(P>0.05)$. MAP recovery from the CPT was slower following saline consumption (1 min recovery: EXP; $15.7 \pm 7.9 \Delta \mathrm{mmHg}$, CON; $12.3 \pm 8.9 \Delta \mathrm{mmHg}, P<0.05$ ). Conclusion: Data showed no difference in cardiovascular responses during HG or the CPT between conditions. BP recovery was delayed by saline consumption following the CPT.
\end{abstract}

\section{KEYWORDS}

exercise pressor reflex, sodium, salt, blood pressure, cold pressor test, handgrip

\footnotetext{
* Corresponding author. Department of Exercise Science and Physical Education, Montclair State University, 1 Normal Avenue, Montclair, NJ 07043, USA. Tel.: +1 973655 3948; fax: +1 973655 5461, E-mail: matthewse@ montclair.edu
} 


\section{INTRODUCTION}

With a majority of Americans consuming more sodium than is recommended [1], understanding how sodium effects health is of the upmost importance. Chronic consumption of a high sodium diet is well known to increase the likelihood of cardiovascular disease and stroke [2], as well as raise blood pressure [3,4]. Additionally, we know that blood sodium concentration and osmolality are controlled by the body to maintain a tight range [5]. When a large dose of sodium is ingested this will trigger the thirst mechanism in an attempt to balance the sodium consumed [6]. Therefore, increases in blood sodium will lead to an increase in blood volume [7]. Understanding how simultaneously elevated blood volume and blood sodium concentration effects blood pressure responses to common stressors such as muscle contraction and cold exposure is a topic that has been far less studied and may affect health outcomes.

Rodent studies have found that chronic consumption of high amounts of sodium combined with water causes enhanced responsiveness of the sympathetic regulatory neurons in the rostral ventrolateral medulla [8-11]. It is believed that both the increased blood sodium concentration and blood volume have an effect on blood pressure [12]. An increase in blood volume can increase stroke volume and cardiac output leading to increased blood pressure [13] if total peripheral resistance is not altered. Likewise, increased plasma osmolality resulting from increased blood sodium enhances baroreflex control of sympathetic activity during intravenous hypertonic saline infusions [14], which may counteract stimulatory effects of sodium and volume loading. Therefore, it is unclear what the effects of high sodium consumption with concomitant fluid intake will have on the acute blood pressure response to physical stress.

No previous studies have examined the effects of a controlled simultaneous oral fluid and sodium load in humans with the induction of physical stress. This will allow for a scientifically controlled model to examine how these two mechanisms impact cardiovascular responsiveness when both are present. Therefore, the purpose of this study was to determine how acute oral fluid and sodium consumption effects blood pressure responses to physical stress. Two studies were performed and presented within this manuscript. Study-1: Participants consumed $423 \mathrm{~mL}$ of a $154 \mathrm{mmol} / \mathrm{L}$ sodium saline solution followed by a series of blood draws over $3 \mathrm{~h}$. This was done to determine the digestion time required to ensure that blood volume and serum sodium concentration were elevated. Study-2: The same saline solution was consumed, and isometric handgrip ( $\mathrm{HG}$ ) and a cold pressor test (CPT) were performed to examine the effects of a simultaneous increase in blood volume and serum sodium on cardiovascular responses. We hypothesized that there would be an exaggerated pressor response to HG and the CPT after the consumption of the saline solution when compared to a control trial.

\section{METHODS}

\section{Screening visits}

All experimental procedures and protocols were approved by the Montclair State University Institutional Review Board, and the study conformed to the standards outlined in the Declaration of Helsinki. Verbal and written consent were obtained voluntarily from all participants before participation. Participants were asked to fill out a health history questionnaire and a general physical activity questionnaire. Height, weight, and body mass index (BMI) were 
measured. The study participants were then given a standard sodium free meal (oats and brown sugar) to take home and instructed to consume the meal no less than 4 hours prior to their experimental and control visits. With the exception of plain water, participants were asked to fast following the controlled meal until after the visit. Participants were also instructed to avoid consuming caffeine $12 \mathrm{~h}$ prior to the visit and avoid strenuous activity, over the counter drug use, and alcoholic beverages $24 \mathrm{~h}$ prior to each visit. Exclusion criteria for this study included a history of cardiovascular disease, hypertension, tobacco use, and obesity (BMI $>30 \mathrm{~kg} / \mathrm{m}^{2}$ ). All participants were generally healthy and between the ages of 18-50 yrs. Research visit time of day varied based on subject availability.

\section{Oral saline protocol}

Upon arrival to the laboratory, participants were asked to provide a urine sample for determination of urine specific gravity. If the participant had a urine specific gravity $\geq 1.020$ [15] (Cambridge Instruments Inc., NY, USA), they were sent home and their visit was rescheduled. If urine specific gravity was appropriate, participants were asked to consume a saline beverage with a sodium concentration equivalent to normal saline, $423 \mathrm{~mL}$ of deionized water with $3.8 \mathrm{~g}$ of table salt $\left(\mathrm{Na}^{+}: 1500 \mathrm{mg}, 154 \mathrm{mmol} / \mathrm{L}\right)$, over a span of less than $5 \mathrm{~min}$. The researchers utilized a $1500 \mathrm{mg}$ dose of sodium as it is in line with the American Heart Association's recommended upper limit of sodium per day, and because it is a dose of sodium that is plausible for a single high sodium meal (e.g. Big MAC ${ }^{\circledR}$ Combo Meal $=1635$ mg; Bacon \& Cheese WHOPPER ${ }^{\circledR}$ Sandwich $=1560 \mathrm{mg})$.

\section{Study 1: Time course of plasma volume and serum sodium alterations}

Eight young healthy adults ( 5 men, 3 women) participated in study 1 (age: $27 \pm 2$ years; height $173 \pm 5 \mathrm{~cm}$; body mass $81.8 \pm 6.1 \mathrm{~kg}$; body mass index $\left.27.2 \pm 1.5 \mathrm{~kg} / \mathrm{m}^{2}\right)$. A baseline blood sample was taken from each participant in a supine position prior to saline consumption. Following oral saline consumption, a supine blood sample was obtained every $30 \mathrm{~min}$ for $3 \mathrm{~h}$. Between blood draws participants rested quietly in the seated position. Blood samples were obtained within $\sim 1$ min of laying supine at each timepoint. Hemoglobin (HemoCue America, CA, USA), hematocrit (microcapillary reader, International Equipment Company, MA, USA), and serum sodium (EasyLyte Electrolyte Analyzer, Medica Corporation, MA, USA) were assessed. Changes in hemoglobin and hematocrit were used to calculate changes in plasma volume, red blood cell volume, and total blood volume [16]. The results of study 1 were used to determine that $90 \mathrm{~min}$ of digestion time are necessary for both total blood volume and serum sodium to be elevated following normal saline consumption (see Results section). Therefore, a 90 min digestion period was used in study 2 .

\section{Study 2: Cardiovascular responses to physical stress following normal saline consumption}

Sixteen participants were tested for study 2 ( 9 men, 7 women; age $26 \pm 1$ years, height $169 \pm 3 \mathrm{~cm}$, weight $71.2 \pm 3.7 \mathrm{~kg}$, and body mass index $24.9 \pm 0.9)$. Study 2 participants were not the same participants as study 1 . A control visit with no saline consumption, and an experimental visit with saline consumption were performed during study 2 . These visits were randomized for each 
participant. During the experimental visit a 90 min waiting period (see study 1 results) was given to allow for digestion following saline consumption prior to HG and CPT trials.

\section{HG protocol}

The isometric HG trial was performed similarly to previous studies [17-19]. Briefly, maximal voluntary contraction (MVC) was assessed by a handgrip dynamometer (ADInstruments, Colorado Springs, CO, USA) using their dominant hand. Participants underwent three MVC trials separated by approximately $1 \mathrm{~min}$, and the highest stable value was used as the MVC. A 5 min resting baseline was collected followed by a 2 min period of isometric $\mathrm{HG}$ at $\approx 30 \% \mathrm{MVC}$. Visual feedback was given to allow the participants to maintain the proper HG force. In the final $5 \mathrm{~s}$ of the $2 \mathrm{~min}$ of $\mathrm{HG}$, an occlusion cuff was inflated to suprasystolic pressure $(>240 \mathrm{mmHg}$ ) and maintained for $2 \mathrm{~min}$ to cause a period of post exercise ischemia (PEI). Following the $2 \mathrm{~min}$ of PEI, an additional 2 min of recovery data was recorded. Following the HG trial, at least 10 min of quiet rest was given, and it was confirmed that resting blood pressure was stable and near baseline levels before any other tests were performed.

\section{CPT protocol}

Following the HG trial a CPT was then administered to determine the BP and heart rate (HR) responses to a non-exercise pressor stimulus [20]. Two minutes of baseline measurements were recorded. The participants then placed their dominant hand in an ice bath for $2 \mathrm{~min}$, and immediately followed by a 2 min recovery period.

\section{Instrumentation}

Automated brachial artery blood pressures (Omron BP785N, Omron Healthcare Inc., Lake Forest, IL, USA) were taken to obtain accurate absolute resting values. Beat-by-beat finger blood pressure was measured by a Human Non-Invasive Blood Pressure Continuous Monitor placed on the middle finger of the non-dominant hand (ADInstruments, Colorado Springs, CO, USA). Heart rate was measured using a lead II electrocardiogram (ADInstruments, Colorado Springs, CO, USA). Respiratory movements were monitored using a strain-gauge pneumograph (Pneumotrace II, ADInstruments, Colorado Springs, CO, USA) which was placed over the abdomen and done to ensure that the participant did not perform a Valsalva maneuver during the HG protocol. HG force, occlusion cuff pressure, HR, respiratory abdominal movement, finger blood pressure, and model flow derived cardiac output, stroke volume, and peripheral resistance [21] were recorded continuously using ADInstruments PowerLab with LabChart 8 Pro software (ADInstruments, Colorado Springs, CO, USA).

\section{Statistical analysis}

Blood alterations from study 1 were analyzed for the effect of time (treatment follow up) using a one-way ANOVA with repeating measures. The Dunnett's multiple comparison post hoc test was used when appropriate to compare time point results compared to the baseline for all oneway ANOVA results. Resting values were compared between conditions using paired $t$-tests. Comparisons of cardiovascular variables for the HG/PEI and the CPT were compared in $60 \mathrm{~s}$ intervals using repeated measures two-way ANOVA with the main factors of treatment and 
time. Scheffe post hoc correction was performed when appropriate to determine differences between time points within and between conditions. The immediately preceding rest period was used for the baseline values of each trial. Results were reported as means $\pm \mathrm{SD}$, and the $\alpha$-level was set at $P<0.05$. All data, including data not shown, is available at: https://digitalcommons. montclair.edu/data/7/.

\section{RESULTS}

\section{Study 1}

The baseline values taken immediately prior to saline consumption were: serum sodium $132.2 \pm$ $6.6 \mathrm{~g} / \mathrm{dL}$; urine specific gravity $1.007 \pm 0.007 \mathrm{sgu}$; systolic blood pressure (SBP) $117 \pm 14 \mathrm{mmHg}$; diastolic blood pressure (DBP) $70 \pm 7 \mathrm{mmHg}$; and mean arterial pressure (MAP) $86 \pm 7 \mathrm{mmHg}$. Hemoglobin decreased $(P<0.05)$ from baseline starting at $60 \mathrm{~min}$ (each $P<0.05)$ and remained depressed for the remainder of the time trial (base $13.9 \pm 0.9,30 \mathrm{~min} 13.5 \pm 1.0,60 \mathrm{~min} 13.6 \pm$ $1.0,90 \mathrm{~min} 13.4 \pm 1.1,120 \mathrm{~min} 13.5 \pm 1.2,150 \mathrm{~min} 13.5 \pm 1.1,180 \mathrm{~min} 13.3 \pm 1.1 \mathrm{~g} / \mathrm{dL})$. Hematocrit also decreased from baseline, but did not reach significance (each $P<0.05$ ) until 150 $\min$ (base $45.0 \pm 3.6,30 \min 44.5 \pm 3.2,60 \min 43.8 \pm 3.0,90 \min 43.4 \pm 3.7,120 \min 43.7 \pm$ $3.6,150 \mathrm{~min} 42.5 \pm 2.9,180 \mathrm{~min} 42.7 \pm 3.5 \%)$. Total blood volume increased $(P<0.05)$ from baseline by $90 \mathrm{~min}$, and remained elevated throughout the trial (Fig. 1). Serum sodium increased significantly from baseline at each time point $(P<0.05)$, except $60 \mathrm{~min}(P>0.05)$ (Fig. 1). Plasma volume increased $(P<0.05)$ from baseline by $60 \mathrm{~min}$ (Fig. 1$)$. There was no change in red blood cell volume throughout the trial (all time points $P<0.05$ ). HR decreased from baseline at all time points (base $67 \pm 8,30 \mathrm{~min}-8 \pm 8,60 \mathrm{~min}-8 \pm 9,90 \min -9 \pm 9,120 \mathrm{~min}-8 \pm 6$, $150 \mathrm{~min}-12 \pm 6,180 \mathrm{~min}-11 \pm 7 \% \Delta \mathrm{bpm}$; all $P<0.05)$. Neither SBP, DBP, or MAP were altered by saline consumption $(P>0.05)$.

\section{Study 2}

Baseline readings for the control and experimental visits were taken immediately prior to the HG trial. There were no significant differences $(P>0.05)$ between the experimental and control visits for resting brachial artery SBP (EXP: $118 \pm 15 \mathrm{mmHg}$; CON: $121 \pm 25 \mathrm{mmHg}$ ), DBP (EXP: $58 \pm 13 \mathrm{mmHg}$; CON: $58 \pm 11 \mathrm{mmHg}$ ), and MAP (EXP: $76 \pm 12 \mathrm{mmHg}$; CON: $75 \pm 13$ $\mathrm{mmHg})$. Resting HR was significantly lower $(P<0.05)$ following saline consumption $(\mathrm{EXP}: 59 \pm$ $10 \mathrm{bpm})$ vs the control visit (CON: $63 \pm 12 \mathrm{bpm})$. Urine specific gravity was not different between conditions (EXP: $1.009 \pm 0.006$; CON: $1.008 \pm 0.006 \mathrm{sgu}$ ).

\section{Handgrip}

During HG the two-way ANOVA time effect was statistically significant for all variables $(P<0.05)$, but the condition and interaction effects were not significant $(P>0.05)$ for any variable.

In both the saline and control visits, SBP, DBP, and MAP were significantly elevated $(P<0.05)$ during HG and PEI when compared to baseline (see Fig. 2 for MAP data). SBP remained elevated above baseline $(P<0.05)$ in both conditions during the first minute of recovery, while DBP and MAP returned immediately to baseline levels. In both conditions HR increased $(P<0.05)$ during HG. HR returned to baseline $(P>0.05)$ during minute one of PEI in the control condition and 


\section{A}

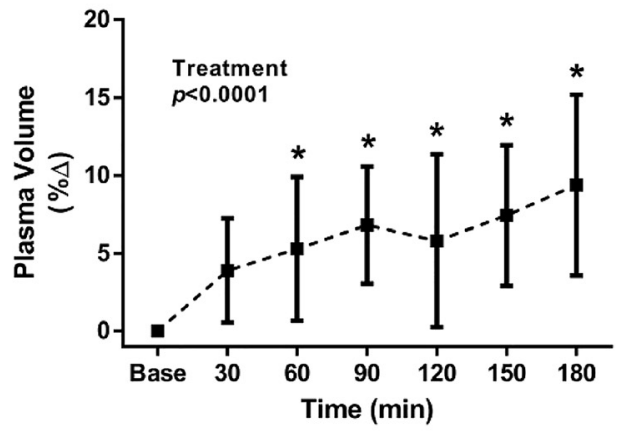

B

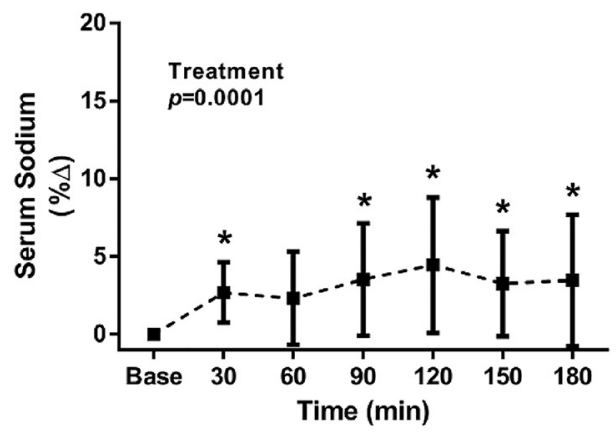

C

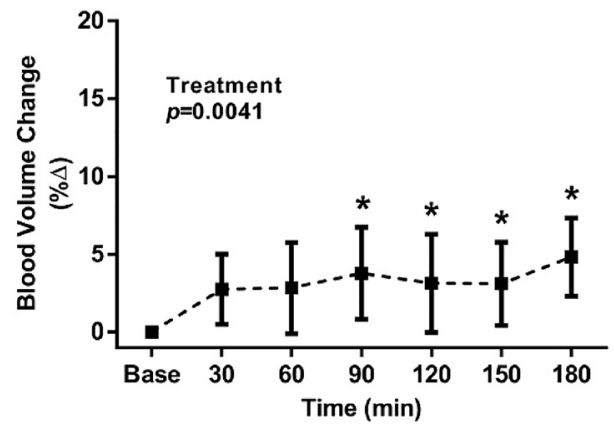

Figure 1. Percent change following oral saline consumption of plasma volume (A), serum sodium (B), and total blood volume $(\mathrm{C})$ over time from baseline (Base). Values are mean $\pm \mathrm{SD} .{ }^{*} P<0.05$ for percent change from baseline 


\section{A}

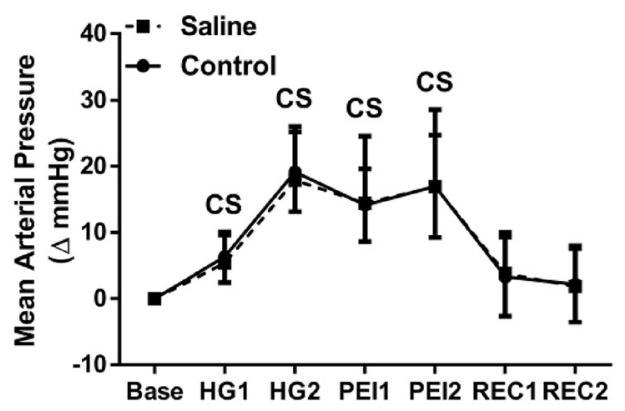

B

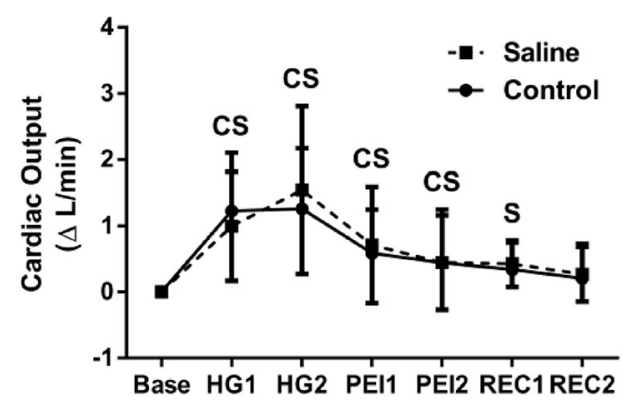

C

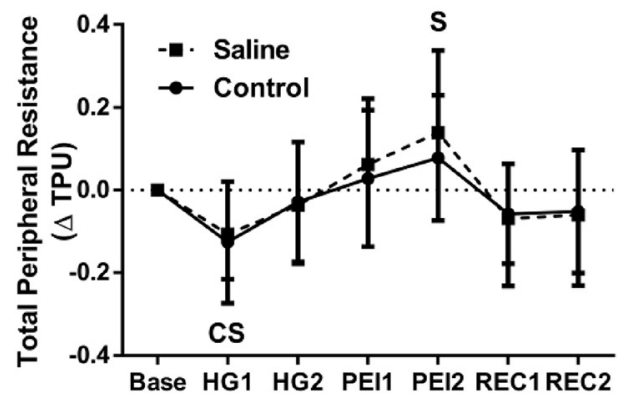

Figure 2. Percent change following oral saline consumption (dashed line with squares) vs. control (solid line with circles) of mean arterial pressure (A), cardiac output (B), and total peripheral resistance (C) over time from baseline (Base) during the handgrip protocol. Hand grip 1st minute (HG1), hand grip 2nd minute (HG2), post-exercise ischemia 1st minute (PEI1), post-exercise ischemia 2nd minute (PEI2), recovery 1 st minute (REC1), recovery 2 nd minute (REC2). Values are mean \pm SD. C $P<0.05$ for control condition vs. baseline value. $\mathrm{S} P<0.05$ for saline condition vs. baseline 


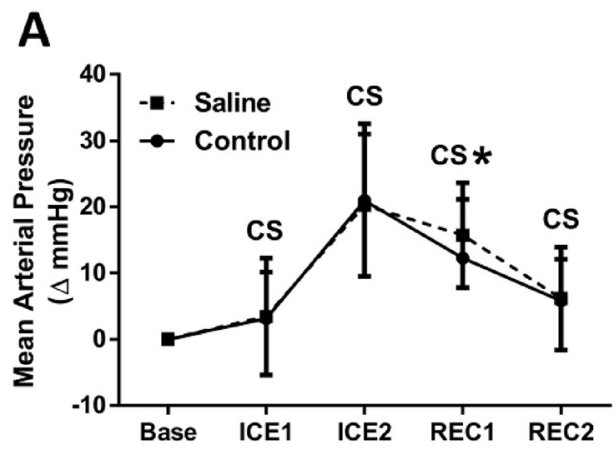

B
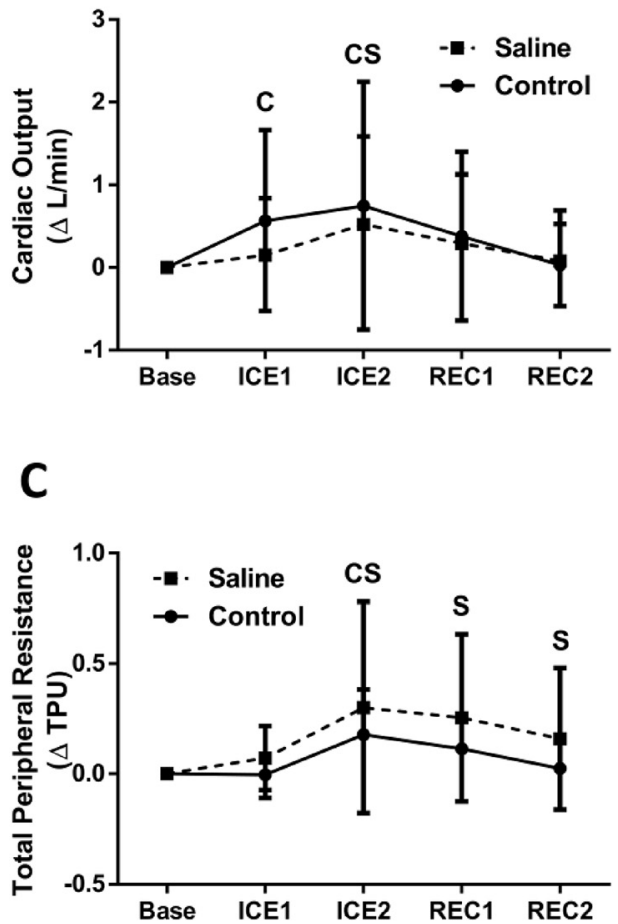

Figure 3. Percent change following oral saline consumption (dashed line with squares) vs. control (solid line with circles) of mean arterial pressure (A), cardiac output (B), and total peripheral resistance (C) over time from baseline (Base) during the cold pressor test. Cold pressor test 1st minute (ICE1), cold pressor test 2nd minute (ICE2), recovery 1st minute (REC1), recovery 2nd minute (REC2). Values are mean \pm SD. C $P$ $<0.05$ for control condition vs. baseline value. $\mathbf{S} P<0.05$ for saline condition vs. baseline. ${ }^{\star} P<0.05$ for experimental condition vs. control 
minute two of PEI in the saline condition. Stroke volume was significantly elevated $(P<0.05)$ by the second minute of HG, with significant values remaining throughout PEI in both conditions. Stroke volume was significantly elevated $(P<0.05)$ in both conditions during minute one of recovery, but only in the control condition during minute two of recovery. Cardiac output $(\mathrm{Q})$ increased $(P<0.05)$ from baseline throughout HG and PEI for both conditions, with only the saline condition remaining elevated into minute one of recovery (Fig. 2). In both conditions, total peripheral resistance (TPR) showed a transient decrease $(P<0.05)$ from baseline during minute one of HG, with significant elevation $(P<0.05)$ found in minute two of PEI for the saline condition only (Fig. 2).

\section{Cold pressor test}

The CPT two-way ANOVA time effect was statistically significant for all variables $(P<0.05)$, but the condition effect was not significant for any variable $(P>0.05)$. However, there was a significant interaction effect for all blood pressure variables, i.e. SBP, DBP, and MAP $(P<0.05)$.

SBP increased from baseline during the second minute of the CPT, and remained significantly elevated $(P<0.05)$ throughout recovery in both conditions. The saline condition was significantly greater $(P<0.05)$ than the control condition during the first minute of recovery (Saline REC1 $17.8 \pm 13.6 \Delta \mathrm{mmHg}$, Control REC1 $12.3 \pm 11.4 \Delta \mathrm{mmHg}$ ) suggesting a slower SBP recovery. Both DBP and MAP were significantly elevated $(P<0.05)$ from baseline from minute one through minute two of recovery (see Fig. 3 for MAP data). Similar to SBP, both DBP (Saline REC1 $12.5 \pm 6.0 \Delta \mathrm{mmHg}$, Control REC1 $9.7 \pm 7.3 \Delta \mathrm{mmHg}$ ) and MAP (Saline REC1 $15.7 \pm 7.9 \Delta \mathrm{mmHg}$, Control REC1 $12.3 \pm 8.9 \Delta \mathrm{mmHg}$ ) were slower to recovery in the saline condition. In both conditions, HR significantly increased $(P<0.05)$ from baseline during minute one of the $\mathrm{CPT}$, and showed a significant decrease $(P<0.05)$ during minute two of recovery. The control condition showed a significant increase $(P<0.05)$ in SV during minute two of the CPT, which remained during minute one of recovery. The saline condition only showed a significant SV increase $(P<0.05)$ from baseline during minute one of recovery. Q significantly increased $(P<0.05)$ from baseline in minutes $1-2$ in the control condition, while only minute two for the saline condition (Fig. 3). Both conditions showed increases in TPR during minute two of the $\mathrm{CPT}$, with only the saline condition remaining significantly elevated $(P<0.05)$ throughout recovery (Fig. 3).

\section{DISCUSSION}

This investigation examined a controlled simultaneous oral consumption of fluid and sodium to determine its effect on blood pressure responsiveness to physical stress. The major findings of this study were that acute saline consumption causes 1 ) increased in blood volume (via plasma volume) and serum sodium; 2) decreased resting HR, but does not affect cardiovascular responses to isometric HG or the CPT; and 3) slowed blood pressure recovery following the CPT likely driven by a slower recovery of total peripheral resistance. Collectively, these results suggest that while sodium and volume loading may not affect cardiovascular responsiveness to physical stress, it may slow cardiovascular recovery following a strong stimulus such as a CPT.

Previous studies have looked at the effect of chronic high dietary sodium consumption on sympathetic regulatory networks in rats [8-11] and humans [22] and found that high dietary 
sodium causes elevated sympathetic nerve activity. Interestingly, having greater sodium sensitivity is also associated with greater resting sympathetic nerve activity [23]. The effects of acute high dietary sodium consumption have been studied with mixed results. Some studies have shown that acute sodium loading can lead to an increase in cardiovascular and sympathetic responses in rats [24] and humans [25]. Other studies have determined that pressor and sympathetic responses to hypertonic saline infusions were not significant [26]. Recently, an acute high sodium meal was shown not to effect blood pressure responses to maximal dynamic exercise [27]. The current investigation is the first to examine the effects of an acute high sodium meal on blood pressure responses to isometric muscle contraction.

It is possible that the volume loading that was incorporated with the sodium loading during this investigation counteracted the effects of sodium through stimulation of the baroreflex. Baroreflex stimulation through vascular volume loading causes a depressor response to sympathetic excitation and blood pressure [28]. Previous studies where volume loading occurred found significant increases in the control of sympathetic activity [29, 30]. When plasma osmolality increases it can enhance the sensitivity of the baroreflex to control muscle sympathetic nerve activity [14]. The exercise pressor reflex responsiveness is heavily modulated by the baroreflex [28] and may have been dampened by baroreflex activation via volume loading in the present investigation.

Altered cardiovascular reactivity to the CPT has been shown to exist in diseases such as hypertension [31]. In fact, high reactivity to the CPT has been shown to be a predictor of future hypertension [31]. The current investigation found that saline consumption delayed the recovery of blood pressure following the CPT, but not isometric HG. The neural mechanisms are different between HG and the CPT which leads to different response patterns [32]. The CPT primarily brings upon a cardiovascular response via cold induced pain [33], while HG combines feed forward (central command) [34] and efferent (exercise pressor reflex) [35] neural input to drive the cardiovascular responses. Also the CPT is a very strong stimulus [36] while using a 30\% MVC HG is a more moderate intensity stimulus [37]. The differences in neural input or stimulus intensity could explain the differences in blood pressure recovery patterns found in the current investigation.

We recognize that there are some limitations to this study. One limitation is that the participants were in a supine position during the HG and CPT protocols. In the supine position, venous return is maximized leading to high stroke volume and cardiac output [38]. This is different from the upright posture that is most common during waking hours. In the upright posture our bodies must overcome the effects of gravity to return blood to the heart [39]. We also recognize that using a larger muscle group and having participants engage in dynamic exercise, as opposed to isometric exercise, may yield different results. Future investigations should examine the effects of sodium and volume loading during upright, large muscle mass dynamic exercise. The current investigation also has a small sample size which limited our ability to find effects smaller than Cohen's $\mathrm{f}=0.4$ (a strong effect).

\section{CONCLUSION}

The hypothesis of this study was that there would be an exaggerated pressor response to HG and the CPT after the consumption of saline when compared to a control condition. Our data does not support this hypothesis and showed no significant difference in cardiovascular responses 
during HG or the CPT between conditions. However, a modest delay in the recovery of blood pressure and total peripheral resistance was found following the CPT in the saline condition. These findings are important because any increase in the length of time the arteries experience high pressures may increase the blood pressure related cardiovascular damage and the risk of a cardiovascular event.

\section{REFERENCES}

1. Kotchen TA, Cowley AW, Frohlich ED. Salt in health and disease - a delicate balance. N Engl J Med 2013; 368: 2531-2.

2. He FJ, MacGregor GA. A comprehensive review on salt and health and current experience of worldwide salt reduction programmes. J Hum Hypertens 2009; 23: 363-84.

3. Sacks FM, Svetkey LP, Vollmer WM, Appel LJ, Bray GA, Harsha D, et al. Effects on blood pressure of reduced dietary sodium and the Dietary Approaches to Stop Hypertension (DASH) diet. DASH-Sodium Collaborative Research Group. N Engl J Med 2001; 344: 3-10.

4. Whelton PK, Appel LJ, Sacco RL, Anderson CAM, Antman EM, Campbell N, et al. Sodium, blood pressure, and cardiovascular disease: further evidence supporting the American Heart Association sodium reduction recommendations. Circulation 2012; 126: 2880-9.

5. Mattson DL. Importance of the renal medullary circulation in the control of sodium excretion and blood pressure. Am J Physiol Regul Integr Comp Physiol 2003; 284: R13-27.

6. Guyton A. Blood pressure control-special role of the kidneys and body fluids. Science 1991; 252: $1813-6$.

7. He FJ, MacGregor GA. Plasma sodium and hypertension. Kidney Int 2004; 66: 2454-66.

8. Adams JM, Bardgett ME, Stocker SD. Ventral lamina terminalis mediates enhanced cardiovascular responses of rostral ventrolateral medulla neurons during increased dietary salt. Hypertension 2009; 54: 308-14.

9. Adams JM, Madden CJ, Sved AF, Stocker SD. Increased dietary salt enhances sympathoexcitatory and sympathoinhibitory responses from the rostral ventrolateral medulla. Hypertension 2007; 50: 354-9.

10. Pawloski-Dahm CM, Gordon FJ. Increased dietary salt sensitizes vasomotor neurons of the rostral ventrolateral medulla. Hypertension 1993; 22: 929-33.

11. Stocker SD, Madden CJ, Sved AF. Excess dietary salt intake alters the excitability of central sympathetic networks. Physiol Behav 2010; 100: 519-24.

12. Farquhar WB, Paul EE, Prettyman AV, Stillabower ME. Blood pressure and hemodynamic responses to an acute sodium load in humans. J Appl Physiol 2005; 99: 1545-51.

13. Julius S, Pascual AV, Sannerstedt R, Mitchell C. Relationship between cardiac output and peripheral resistance in borderline hypertension. Circulation 1971; 43: 382-90.

14. Wenner MM, Rose WC, Delaney EP, Stillabower ME, Farquhar WB. Influence of plasma osmolality on baroreflex control of sympathetic activity. Am J Physiol Heart Circ Physiol 2007; 293: H2313-9.

15. McDermott BP, Anderson SA, Armstrong LE, Casa DJ, Cheuvront SN, Cooper L, et al. National athletic trainers' association position statement: fluid replacement for the physically active. J Athl Train 2017; 52: 877-95.

16. Dill DB, Costill DL. Calculation of percentage changes in volumes of blood, plasma, and red cells in dehydration. J Appl Physiol 1974; 37: 247-8. 
17. Greaney JL, Matthews EL, Boggs ME, Edwards DG, Duncan RL, Farquhar WB. Exaggerated exercise pressor reflex in adults with moderately elevated systolic blood pressure: role of purinergic receptors. Am J Physiol Heart Circ Physiol 2014; 306: H132-41.

18. Greaney JL, Matthews EL, Wenner MM. Sympathetic reactivity in young women with a family history of hypertension. Am J Physiol Heart Circ Physiol 2015; 308: H816-22.

19. Matthews EL, Greaney JL, Wenner MM. Rapid onset pressor response to exercise in young women with a family history of hypertension. Exp Physiol 2017; 102: 1092-9.

20. Victor RG, Leimbach WN, Seals DR, Wallin BG, Mark AL. Effects of the cold pressor test on muscle sympathetic nerve activity in humans. Hypertension 1987; 9: 429-36.

21. Harms MPM, Wessling KH, Pott F, Jenstrup M, Van Goudever J, Secher NH, et al. Continuous stroke volume monitoring by modelling flow from non-invasive measurement of arterial pressure in humans under orthostatic stress. Clin Sci 1999; 97: 291-301.

22. Kopp UC, Jones SY, DiBona GF. Afferent renal denervation impairs baroreflex control of efferent renal sympathetic nerve activity. Am J Physiol Regul Integr Comp Physiol 2008; 295: R1882-90.

23. Matthews EL, Brian MS, Edwards DG, Stocker SD, Wenner MM, Farquhar WB. Blood pressure responses to dietary sodium: association with autonomic cardiovascular function in normotensive adults. Auton Neurosci 2017; 208: 51-6.

24. Yamauchi K, Tsuchimochi H, Stone AJ, Stocker SD, Kaufman MP. Increased dietary salt intake enhances the exercise pressor reflex. Am J Physiol Heart Circ Physiol 2014; 306: H450-4.

25. Brian MS, Matthews EL, Watso JC, Babcock MC, Wenner MM, Rose WC, et al. The influence of acute elevations in plasma osmolality and serum sodium on sympathetic outflow and blood pressure responses to exercise. J Neurophysiol 2018; 119: 1257-65.

26. Weiss ML, Claassen DE, Hirai T, Kenney MJ. Nonuniform sympathetic nerve responses to intravenous hypertonic saline infusion. J Auton Nerv Syst 1996; 57: 109-15.

27. Migdal KU, Robinson AT, Watso JC, Babcock MC, Serrador JM, Farquhar WB. A high salt meal does not augment blood pressure responses during maximal exercise. Appl Physiol Nutr Metab 2020; 45: 123-8.

28. Potts JT, Li J. Interaction between carotid baroreflex and exercise pressor reflex depends on baroreceptor afferent input. Am J Physiol 1998; 274: H1841-7.

29. Charkoudian N, Eisenach JH, Joyner MJ, Roberts SK, Wick DE. Interactions of plasma osmolality with arterial and central venous pressures in control of sympathetic activity and heart rate in humans. Am J Physiol Heart Circ Physiol 2005; 289: H2456-60.

30. Charkoudian N, Martin EA, Dinenno FA, Eisenach JH, Dietz NM, Joyner MJ. Influence of increased central venous pressure on baroreflex control of sympathetic activity in humans. Am J Physiol Heart Circ Physiol 2004; 287: H1658-62.

31. Menkes MS, Matthews KA, Krantz DS, Lundberg U, Mead LA, Qaqish B, et al. Cardiovascular reactivity to the cold pressor test as a predictor of hypertension. Hypertension 1989; 14: 524-30.

32. Moriyama $\mathrm{K}$, Ifuku $\mathrm{H}$. Increased cardiovascular reactivity to the cold pressor test is not associated with increased reactivity to isometric handgrip exercise. Eur J Appl Physiol 2010; 108: 837-43.

33. Peckerman A, Hurwitz BE, Saab PG, Llabre MM, McCabe PM, Schneiderman N. Stimulus dimensions of the cold pressor test and the associated patterns of cardiovascular response. Psychophysiology 2018; 31: 282-90.

34. Goodwin GM, McCloskey DI, Mitchell JH. Cardiovascular and respiratory responses to changes in central command during isometric exercise at constant muscle tension. J Physiol 1972; 226: 173-90.

35. Kaufman MP, Hayes SG. The exercise pressor reflex. Clin Auton Res 2002; 12: 429-39.

36. Peckerman A, Saab PG, McCabe PM, Skyler JS, Winters RW, Llabre MM, et al. Blood pressure reactivity and perception of pain during the forehead cold pressor test. Psychophysiology 1991; 28: 485-95. 
37. Kagaya A, Homma S. Brachial arterial blood flow during static handgrip exercise of short duration at varying intensities studied by a Doppler ultrasound method. Acta Physiol Scand 2003; 160: 257-65.

38. McMichael J, Sharpey-Schafer EP. Cardiac output in man by a direct Fick method: effects of posture, venous pressure change, atropine, and adrenaline. Br Heart J 1944; 6: 33-40.

39. Granath A, Jonsson B, Strandell T. Studies on the central circulation at rest and during exercise in the supine and sitting body position in old men. Acta Med Scand 2009; 169: 125-6. 